[Berliner entomologische Zeitschrift XVIII. 1874.]

\title{
Neue Heteroptera aus Ungarn
}

\author{
beschrieben von
}

Dr. G. v. Horváth in Pest.

1. Zosmenus porcatus nov. spec.

Breviter-ovalis, albidus; antennis, articulo apicali fusco excepto, pedibusque flavescentibus; thorace hemelytrisque fortiter punctatis; thorace brevi, transverso, hemelytris angustiore, carinis quinque parallelis, parce nigro-punctatis, harum tribus mediis percurrentibus, instructo; hemelytris sese haud tegentibus, clavo, corio et membrana haud distinctis, latitudine parte sexta longioribus, marginibus lateralibus et costis elevatis parce nigro-punctatis. - Long. $2 \frac{1}{2}$, lat. $1 \frac{1}{4}$ mill.

Kurz eiförmig, etwas gewölbt; graulich weifs, mit schwach röthlichem oder grünlichem Anfluge. Thorax oben und unten, insbesondere aber die Halbdecken dicht und tief netzmaschig eingestochen punktirt. Kopf fein punktirt, mit gerade vorstehenden Jochhörnern. Fühler lehmgelb, Endglied bräunlich. Thorax kurz, fast doppelt so breit als lang, nach vorn sehr schwach verengt; Seitenrand blattartig, in der Mitte kaum ausgeschweift, Halswinkel stumpf abgerundet; Vorderrand etwas eingebogen, Hinterrand gerade; Scheibe mit fünf geraden parallelen, hier und da schwarz getüpfelten Kielen, von welchen die drei mittleren durchlaufend, einander genähert und etwas stärker sind, als die zwei nach vorn abgekürzten, aber noch immer ziemlich starken äufseren Seitenkiele. Schildchen am Grunde etwas gelblich. Halbdecken kurz elliptisch, nur um ein Sechstel länger als zusammen breit, breiter als der Thorax, mit geraden Innenrändern aneinander liegend, sich nicht deckend; Clavus, Corium und Membran undeutlich von einander geschieden; alle Rippen sind zu ziemlich starken Kielen erhoben, welche sowie der Aufsenrand spärlich und sehr klein schwarz ge- 
fleckt sind. - Hinterleib fein punktirt, gelblichweifs, bei einem Exemplar (ठ઼) grünlichweifs mit drei Reihen schwärzlichen Fleckchen. Beine lehmgelb.

Durch die angegebenen Merkmale von allen mitteleuropäischen Arten verschieden. Am nächsten scheint er mit Zosmenus atriplicis Frey-Gelsner aus Sarepta verwandt, von diesem aber durch bedeutendere Grölse und statt drei, fünf Thoraxkiele hinlänglich verschieden zu sein.

Drei Ex. von den Sandhaiden bei Pest. (Mus. Hung.)

\section{Agramma minutum nov. spec.}

Oblongo-ovatum, nigrum; antennarum articulis crassiusculis, arliculo tertio apice, quarto toto ferrugineis, his crassitudine aequalibus; thorace postice transversim impresso, marginibus lateralibus sensim arcuatis, margine antica et processus scutellaris apice angustissime testaceis; hemelytris convexis, sese haud tegentibus et basi nigricantibus, testaceis; pedibus ferrugineis, femoribus nigricantibus. - Long. $1 \frac{3}{4}$, Lat. $\frac{3}{5}$ mill.

Länglich eiförmig, schwarz. Kopf fein punktirt. Fühler kurz und kräftig, sehr fein gekörnt, schwarz, drittes Glied an der Spitze rostroth und etwas verschmälert, aber nicht dünner als das ganz rostrothe spindelförmige Endglied. Thorax tief und grob punktirt, mit schwach gerundeten und vorn schnell verengten Seitenrändern, hinter der Wölbung mit einer deutlichen Quervertiefung; Vorderrand äufserst schmal schalgelb gesäumt, Spitze des kurzen Processus in geringer Ausdehnung ebenso gefärbt; Mittelkiel schwach und undeutlich. Halbdecken genetzt, schalgelb, am Grunde schwärlich, der Länge und Breite nach ziemlich stark gewölbt, parallel aneinander liegend, sich nicht deckend, den Hinterleib nur wenig überragend. - Rand der Wangenplatten sowie die Brustplatten und Beine rostroth; Schenkel schwärzlich, am Grund und Ende etwas heller.

Diẻ kleinste europäische Art, dem A. la etum Fall. am nächsten stehend und von Flor (Rhynch. Livl. I. p. 325), der ein bei Laibach gefangenes Stück dieser Art vor sich gehabt zu haben scheint, nur für eine mit rudimentären Flügeln ausgestattete Form der ersteren gehalten. Ich halte sie für eine selbstständige Art, welche sich durch folgende specifische Merkmale sehr gut begründen läfst: die kürzeren, kräftigeren Fübler, das ganz rothrothe Fühlerendglied, welches nicht dicker als das vorletzte ist, die am Grunde geschwärzten, feiner genetzten Halbdecken und die con- 
stant dunkel gefärbten Schenkel. Die eigenthümliche Bildung des Thorax und der Halbdecken könnte ihren Grund sehr wohl blos in der rudimentären Entwickelung der Flügel haben.

Drei Exemplare aus den Ofner Bergen. (Mus. Hung.)

\section{Monanthia flavipes nov. spec.}

Oblongo-ovata, glabra, nitida; capite antennisque nigris, harum articulo tertio brevi, cylindrico, apice oblique truncato; thorace castaneo, vesicula antica et processu scutellari, carinis tribus parallelis instructo, nec non hemelytris stramineis; abdomine pedibusque totis testaceis, tibiis basin versus modice angustatis. - Long. $3 \frac{1}{2}-$ $3 \frac{2}{3}$, Lat. $1 \frac{1}{3}-1 \frac{1}{2}$ mill.

Länglich eiförmig, glänzend, unbehaart. Kopf schwarz, vorn am Scheitel mit zwei sehr kurzen, eng aneinander liegenden gelben Dornen. Fühler kurz und kräftig, schwarz, fein anliegend behaart; drittes Glied cylindrisch, mit den übrigen gleichdick, weniger als doppelt so lang wie das Endglied, am Ende schief nach unten hinten abgestutzt. Thorax vorn gerade, mit nach hinten fünfeckiger, oben gekielter, schmutzig strohgelber Halsblase, auf der Wölbung kastanienbraun, deutlich punktirt, ungekielt, die Stelle der Kiele nehmen zuweilen drei schwärzlich durchscheinende Streifen ein, welche hinten in die drei geraden, ziemlich starken Kiele des strohgelben Processus übergehen. Halsblase und Processus, sowie die ebenfalls strohgelben Halbdecken netzmaschig. - Brust schwarz oder schwärzlich; Brust- und Wangenplatten weifsgelb. Bauch sammt den Beinen schalgelb; letztes Tarsenglied an der Spitze schwarz. Beine kurz, kräftig; Schienen gegen den Grund zu etwas verschmälert.

Der M. albida Herr.-Sch. und Eryngii Latr. ähnlich; sie unterscheidet sich von diesen aufser der constanten Färbung der Beine und des Hinterleibs, durch die kurzen, nur auf der Hinterhälfte des Thorax vorhandenen Kiele, durch kürzere, kräftigere Beine und Fühler und durch das kurze dritte Fühlerglied, welches bei diesen zwei Arten bedeutend mehr als doppelt so lang ist wie das Endglied. Aufserdem unterscheidet sie sich noch von $M$. albida durch die Bildung der Schienen, von M. Eryngii durch das gleichmäfsig cylindrische dritte Fühlerglied. - Von der mir nur nach der Beschreibung bekannten M. Olivieri Put. aus Algier, mit der sie auch verwandt zu sein scheint, unterscheidet sie sich durch die Färbung des Thorax und des Hinterleibs, durch gänzlichen Mangel aller drei Kiele - auch des Mittelkieles - auf der 
Wölbung des Thorax u.s. w., besonders aber durch das mit den übrigen gleichdicke dritte Fühlerglied, welches bei M. Olivieri "plus mince que le second" sein soll.

Auf den Bergen bei Ofen und Fünfkirchen von Mai bis Anfang August nicht sebr selten. (Mus. Hung. et Coll. Horv.)

\section{Aradus sordidus nov. spec.}

Oblongo-ovatus, niger; antennarum articulo secundo basin versus leviter gracilescenti, duobus ultimis aeque longis, simul sumtis sublongiore; rostro mesostethii medium attingente; thorace postice angustissime flavo-marginato, marginibus lateralibus minutissime crenulatis; hemelytris flavo nigroque variis, basi extus dilatitis; membrana hyalina, sordide fusco-maculata; coxis femorumque apice, nec non maculis transversis marginalibus abdominis flavescentibus. Long. $4 \frac{1}{2}-5 \frac{1}{2}$, Lat. $1 \frac{3}{4}-2 \frac{1}{3}$ mill.

Länglich eiförmig, schwarz oder schwarzbraun. Fühler länger als der Kopf, ganz einfarbig dunkel; zweites Glied gegen die Basis zu allmälig verdünnt, etwas länger als die beiden gleichlangen Endglieder zusammen. Schnabel auf die Mitte der Mittelbrust reichend. Thorax am Hinterrande sehr wenig ausgeschnitten und sehr schmal gelb gesäumt; Seitenrand sehr fein gekerbt, gleichmärsig abgesetzt und etwas aufgebogen, an den Schultern gerundet, vorn stark geschweift; Rückenkiele gerade. Schildchen länglich dreieckig, mit flachbogigen Seiten und aufgebogenen Seitenrändern, in der Mitte etwas gewölbt. Halbdecken gelblich, unregelmälsig schwarz oder schwarzbraun gefleckt, an der Wurzel und Spitze stets dunkel, hinter der Wurzel nach aufsen eine grössere helle Stelle; Aufsenrand am Grunde bogig erweitert und etwas aufgebogen. Membran hyalin, zwischen den gebräunten Rippen mit schwarzen oder schwarzbraunen Querflecken. Beine braunschwarz, Hüften und Schenkelende gelblich. Hinterleib an den Segmentecken oben und unten mit gelblichen Querflecken oder Querstreifen. Hinterrand der Abdominalsegmente unten winkelig ausgeschnitten; beim $\sigma^{\top}$ das fünfte am stärksten, so dafs es in der Mittellinie weniger als ein Drittel so lang ist wie das hinten bogig ausgerandete breite sechste Segment; beim $Q$ ist das fünfte und sechste Abdominalsegment in der Mitte gerade, gleichlang, das erste Genitalsegment in der Mittellinie doppelt so lang wie.das zweite, und nur wenig kürzer als das sechste Abdominalsegment.

Steht dem A. lugubris Fall. zunächst und unterscheidet sich von demselben durch die Färbung der Fühler, durch stärker vor- 
stehende Halsecken, durch die am Grunde ausgebogenen Coriumränder, sowie durch die Bildung der Fühler und der Abdominalund Genitalsegmente.

Vier Stück aus der Ofner Gegend. (Mus. Hung.)

\section{Corisa Frivaldszkyi nov. spec.}

Oblonga, laevis, nitida, alata; vertice rotundata, fronte albidopiloso; thorace longitudine parum latiore hemelytrisque nigro-fuscis, crebre pallideque minute flavo-conspersis, angulo interno clavi prope basin macula flava ornato; subtus cum capite pedibusque flavida, pectore medio nigro. - Long. $6 \frac{1}{2}$, Lat. $2 \frac{1}{3}$ mill.

o. Palis subuliformibus, dorso subarcuatis; fovea frontali lata, leviter impressa, oculos vix superante; abdominis basi nigra.

․ Palis subuliformibus; fronte subplana; lobis ani nigris, angustissime flavo-marginatis.

Länglich, oben glatt, glänzend, unbehaart. Kopf gelb, mit den Augen zusammen breiter als der Thorax, vorn gerundet; Scheitel in der Mitte mit einem nach hinten deutlicheren Längskiel, am Hinterrande schmal bräunlich; Stirne mit ziemlich langen, gelblichweifsen Härchen besetzt, beim $\delta$ flach und breit ausgehöhlt, beim \& platt. Thorax nur um ein Viertel breiter als lang, länger als der Kopf, nach hinten dreieckig, vorn mit einem bis etwa auf die Mitte reichenden Längskiel, schwarzbraun mit sehr kleinen gelben, meist queren Fleckchen dicht besetzt, so dafs die Färbung bei schwacher Vergröfserung als schöne Marmorirung erscheint. Clavus und Corium ebenso gefärbt, nur sind die gelben Fleckchen etwas gröfser und verfliefsen oft; am inneren Grundwinkel des Clavus entsteht in Folge Zurücktretens der dunklen Färbung ein grösserer oder kleinerer intensiv gelber Fleck, welcher nur sehr selten ganz fehlt; Randfeld des Corium gelb. Membran gelb, fein und dicht schwarzbraun marmorirt, mit einer deutlichen Rippe, welche eine grofse Zelle einschliefst. Flügel vollkommen entwickelt. Unterseite sammt den Beinen gelb, Brustmitten und Ende des letzten Tarsengliedes an den Mittelbeinen schwarz; erstes, zweites und drittes Bauchsegment beim $\sigma^{\top}$ am Grunde breit schwarz; Afterklappen des 9 schwarz, äufserst fein gelb gerandet. Hinterleibsrücken gelb; am Grunde mehr oder weniger schwarz, zuweilen ganz gelb. Pola beim $\delta$ säbelförmig, beim $q$ pfriemlich.

Eine durch Grölse, Färbung und Thoraxbildung ausgezeichnete Art aus der kleinen Gruppe Cymatia Flor. Sie kann mit den bisher bekannten drei europäischen Arten dieser Gruppe nicht verwechselt werden und schliefst sich in ihrer äufseren Erscheinung mehr den echten Corisa-Arten an.

Von Herrn Custos Joh. v. Frivaldszky mehrere Exemplare bei Pest gesammelt. (Mus. Hung.) 


\section{$2 \mathrm{BHL}$ Biodiversity Heritage Library}

Horváth, Géza. 1874. "Neue Heteroptera aus Ungarn." Berliner entomologische Zeitschrift / herausgegeben von dem Entomologischen Vereine in Berlin 18(3प4), 332-336. https://doi.org/10.1002/mmnd.18740180316.

View This Item Online: https://www.biodiversitylibrary.org/item/36410

DOI: https://doi.org/10.1002/mmnd.18740180316

Permalink: https://www.biodiversitylibrary.org/partpdf/210015

\section{Holding Institution}

Smithsonian Libraries

\section{Sponsored by}

Smithsonian

\section{Copyright \& Reuse}

Copyright Status: Public domain. The BHL considers that this work is no longer under copyright protection.

This document was created from content at the Biodiversity Heritage Library, the world's largest open access digital library for biodiversity literature and archives. Visit BHL at https://www.biodiversitylibrary.org. 